\title{
Methods for the assessment of mitochondrial membrane permeabilization in apoptosis
}

\author{
Lorenzo Galluzzi • Naoufal Zamzami • \\ Thibault de La Motte Rouge • Christophe Lemaire • \\ Catherine Brenner • Guido Kroemer
}

Published online: 6 February 2007

(C) Springer Science + Business Media, LLC 2007

\begin{abstract}
Mitochondrial membrane permeabilization (MMP) is considered as the "point-of-no-return" in numerous models of programmed cell death. Indeed, mitochondria determine the intrinsic pathway of apoptosis, and play a major role in the extrinsic route as well. MMP affects the inner and outer mitochondrial membranes (IM and OM, respectively) to a variable degree. OM permeabilization culminates in the release of proteins that normally are confined in the mitochondrial intermembrane space (IMS), including caspase activators (e.g. cytochrome $c$ ) and caspase-independent death effectors (e.g. apoptosis-inducing factor). Partial IM permeabilization disrupts mitochondrial ion and volume homeostasis and dissipates the mitochondrial transmembrane potential $\left(\Delta \Psi_{\mathrm{m}}\right)$. The assessment of early mitochondrial alterations allows for the identification of cells that are committed to die but have not displayed yet the apoptotic phenotype. Several
\end{abstract}

L. Galluzzi · N. Zamzami · T. de La Motte Rouge · G. Kroemer INSERM, U848,

94805 Villejuif, France

L. Galluzzi · N. Zamzami · T. de La Motte Rouge · G. Kroemer Institut Gustave Roussy,

94805 Villejuif, France

L. Galluzzi · N. Zamzami · T. de La Motte Rouge · G. Kroemer Faculté de Médecine-Université Paris-Sud XI, 94805 Villejuif, France

C. Lemaire $\cdot$ C. Brenner

Université de Versailles/SQY-CNRS UMR 8159,

78035 Versailles, France

G. Kroemer $(\square)$

INSERM, U848, Institut Gustave Roussy, PR1,

38 rue Camille Desmoulins,

F-94805 Villejuif, France

e-mail: kroemer@igr.fr techniques to measure MMP by cytofluorometry and fluorescence microscopy have been developed. Here, we summarize the currently available methods for the detection of MMP, and provide a comparative analysis of these techniques.

Keywords Apoptosis · FACS · Fluorescence microscopy · Fluorochromes $\cdot$ Mitochondrial membrane

permeabilization $\cdot$ Mitochondrial transmembrane potential

$\begin{array}{ll}\text { Abbreviations } & \\ { }^{1} \text { H-NMR } & \text { proton nuclear magnetic resonance } \\ \Delta \Psi_{\mathrm{m}} & \text { mitochondrial transmembrane potential } \\ \text { AIF } & \text { apoptosis-inducing factor } \\ \text { ANT } & \text { adenine nucleotide translocase } \\ \text { APAF-1 } & \text { apoptosis protease activating factor 1 } \\ \text { BH3 } & \text { Bcl-2 homology domain 3 } \\ \text { CMXRos } & \text { chloromethyl-X-rosamine } \\ \text { CypD } & \text { cyclophilin D } \\ \text { Cyt } c & \text { cytochrome } c \\ \text { DiOC } 6 \text { (3) } & 3,3^{\prime} \text { dihexiloxalocarbocyanine iodide } \\ \text { ELISA } & \text { enzyme-linked immunosorbent assay } \\ \text { FACS } & \text { fluorescence-activated cell sorter } \\ \text { FSC } & \text { forward scatter } \\ \text { GFP } & \text { green fluorescent protein } \\ \text { HIV-1 } & \text { human immunodeficiency virus type 1 } \\ \text { HPLC } & \text { high-pressure liquid chromatography } \\ \text { HSP-60 } & \text { heat shock protein of } 60 \text { kDa } \\ \text { JC-1 } & 5,5^{\prime}, 6,6^{\prime} \text {-tetrachloro-1, } 1^{\prime}, 3,3^{\prime}- \\ & \text { tetraethylbenzimidazolcarbocyanine } \\ & \text { iodide } \\ \text { Omi/HtrA2 } & \text { Omi stress-regulated endoprotease/High } \\ & \text { temperature requirement protein A 2 } \\ \text { PT } & \text { permeability transition } \\ \text { PTPC } & \text { permeability transition pore complex } \\ \text { Rh 123 } & \text { rhodamine 123 }\end{array}$


Smac/DIABLO second mitochondria-derived activator of caspase/direct IAP binding protein with a low pI

SSC side scatter

tBid truncated Bid

TMRE tetramethylrhodamine ethyl ester

TMRM tetramethylrhodamine methyl ester

VDAC voltage-dependent anion channel

\section{Intrinsic and extrinsic apoptosis pathways}

Apoptosis is a finely regulated, genetically encoded program by which vertebrates eliminate superfluous, ectopic, mutated or damaged cells. It plays a prominent role during normal embryonic and post-embryonic development, but also in numerous pathological and therapeutic settings [1, 2]. Apoptosis is characterized by phenotypic changes involving the nucleus (pyknosis, i.e. chromatin condensation, and karyorhexis, i.e. nuclear fragmentation), the plasma membrane (phosphatidylserine exposure) and, more generally, the entire cell that progressively shrinks and eventually breaks into several "apoptotic bodies" [3, 4].

Apoptosis may be separated into at least three distinct phases: initiation, integration/decision and execution/degradation. The initiation phase strictly depends on the nature of the lethal signal, which may arise from either the extracellular (extrinsic pathway) or the intracellular (intrinsic) microenvironment. The integration/decision phase implicates numerous pro- and anti-apoptotic molecules, which oppose each other on the battlefield where the cell's fate is decided and the "point-of-no-return" may be trespassed. The final execution phase involves an ensemble of degradative, post-mortem phenomena, which altogether lead to the phenotypic manifestations of apoptosis. Generally, the morphological and biochemical changes that characterize late-stage apoptosis are independent of the initial stimulus [5, 6].

A plethora of different signals can lead to apoptosis, through the activation of distinct but sometimes overlapping molecular pathways. The major and best characterized pathways leading to apoptotic cell death are the extrinsic and intrinsic ones. In the intrinsic pathway, mitochondria play a decisive role. Death-promoting stimuli originating from other subcellular compartments (e.g. the nucleus, lysosomes, the endoplasmic reticulum, or the cytosol) converge on mitochondria where they favor mitochondrial membrane permeabilization (MMP) [7-9]. Upon permeabilization of the mitochondrial outer membrane $(\mathrm{OM})$, intermembrane space (IMS) proteins, that include caspase activators such as cytochrome $c$ (Cyt $c$ ) [10], Omi/HtrA2 (Omi stress-regulated endoprotease/High temperature requirement protein A 2) $[11,12]$ and Smac/DIABLO (second mitochondria-derived activator of caspase/direct IAP binding protein with a low pI)
$[13,14]$, as well as caspase-independent death effectors like apoptosis-inducing factor (AIF) $[15,16]$ and endonuclease $\mathrm{G}$ (EndoG) [17], are released into the cytosol. Cyt $c$ promotes the activation of the initiator caspase- 9 in a direct fashion via the assembly of the apoptosome (together with the apoptosis protease activating factor-1, i.e. APAF-1, and ATP/dATP) [18], while Omi/HtrA2 [11, 12] and Smac/Diablo [13, 14] favor the caspase cascade indirectly, by antagonizing the activity of endogenous inhibitors of caspases, i.e. the inhibitor of apoptosis proteins (IAPs). AIF and EndoG translocate to the nucleus where they mediate chromatin condensation and large-scale DNA fragmentation, independently from caspases $[16,17,19,20]$.

In the extrinsic pathway, the lethal signal comes from the extracellular microenvironment and is transduced within cells either by the ligand-induced activation of death receptors or by the activation of the so-called "dependency receptors," promoted by the absence of their ligands. The death receptors family includes the tumor necrosis factor- $\alpha$ (TNF$\alpha$ ) receptor -1 and CD95/Fas (the receptor of CD95L/FasL) $[21,22]$. The netrin-1 receptors DCC and UNC5H-1, -2 and -3 , on the other hand, represent prototypic dependency receptors [23]. Activated death receptors induce the assembly of the death-inducing signaling complex (DISC), a molecular platform that promotes the dimerization and activation of initiator caspases-8 and -10 [24]. Similarly, the dependency receptors are probably connected to a rapid activation of the caspase cascade [23].

The extrinsic and intrinsic pathways converge on the common degradation phase mediated by executioner caspases- 3 , -6 and -7 [25], but are interconnected also upstream, at the integration/decision phase, at least in some models of apoptosis. Indeed, caspase- 8 induces the proteolytic maturation of the $\mathrm{BH} 3$-only protein Bid, which, in its truncated form (tBid) translocates to mitochondria and favors MMP [21, 26, 27]. tBid acts at mitochondria through the cardiolipin-facilitated interaction with other pro-apoptotic members of the Bcl-2 family (e.g. Bax, Bak) [28], by destabilizing mitochondrial membranes through the insertion of selected lysolipids [29] or by promoting the propagation of $\mathrm{Ca}^{2+}$ signals to the mitochondria [30].

\section{Mitochondrial membrane permeabilization}

Mitochondrial membrane permeabilization (MMP) represents a unifying feature of several models of cell death, and is commonly considered as the "point-of-no-return" in the sequence of events leading to apoptosis [7, 31, 32]. MMP occurs via multiple and complex mechanisms, which may involve only the OM or engage also the inner mitochondrial membrane (IM). With this regard, it has been a matter of debate whether IM actively contributes to MMP or whether IM 
alterations associated with apoptosis would be secondary to regulatory events that affect OM. However, numerous observations point to the active contribution of IM to MMP. This has been particularly substantiated by pharmacological and genetic manipulations of the IM-associated matrix protein cyclophilin D (CypD), and of the IM transmembrane protein adenine nucleotide translocase (ANT) [33-35]. Indeed, pharmacological inhibitors of these proteins (cyclosporin A for CypD and bongkrekic acid for ANT) are able to prevent cell death, at least in some models of apoptosis (in vitro and in vivo) [5, 36]. Interestingly, the viral protein $\mathrm{R}$ (Vpr) from human immunodeficiency virus type I (HIV-1) exerts cytotoxic effects by promoting MMP via direct interaction with ANT (as assessed ex vivo, in purified mitochondria and artificial membranes containing ANT) [37-39].

\section{OM permeabilization}

Classically, $\mathrm{OM}$ is considered freely permeable to solutes and small metabolites up to approximately $5 \mathrm{kDa}$, due to the presence of an abundant protein (the voltage-dependent anion channel, i.e. VDAC), which would permit the diffusion of such molecules through OM. This cut-off, however, is sufficient to ensure the retention of soluble proteins within the IMS, under normal circumstances. At least three distinct mechanisms which originate at the OM have been proposed to explain the increase in OM permeability associated with cell death. (1) Lethal stimuli may activate pro-apoptotic proteins of the Bcl-2 family, which may translocate from the cytosol to $\mathrm{OM}$ (e.g. Bax, Bid) or undergo conformational changes (e.g. Bak) to promote the formation of large homoor hetero-multimeric channels, through which IMS proteins are released [40-43]. (2) Pro-apoptotic factors may act directly on the lipidic component of the OM, or at the lipidprotein interface, thus favoring the formation of pores though which IMS proteins may exit to the cytosol [29, 44-46]. (3) Activated pro-apoptotic members of the Bcl-2 family may interact with components of the permeability transition pore complex (PTPC), thus favoring (or de-inhibiting) the permeability transition (PT) of the IM, that in turn leads to the physical rupture of the OM [47-49]. In this latter case, IM would supply an active contribution to MMP, as we will briefly discuss in the next section.

\section{IM permeabilization}

In contrast to OM, IM is near-to-impermeable to ions, including protons, in healthy cells. IM impermeability is essential for maintaining the proton gradient that is required for oxidative phosphorylation [50,51]. This means that all constituents of the mitochondrial matrix and metabolites have to cross IM in a tightly regulated fashion, via selective channels and transporters. When IM is permeabilized, the proton gradient and the associated mitochondrial transmembrane potential $\left(\Delta \Psi_{\mathrm{m}}\right)$ dissipate immediately, resulting in the functional impairment of the organelle. IM permeabilization also promotes the osmotic swelling of the mitochondrial matrix, a phenomenon that may ultimately lead to the physical rupture of the OM, because the surface area of the IM (with its folded cristae) largely exceeds that of the OM [49, 52, 53]. IM permeabilization may occur accidentally, during primary necrosis or as a consequence of OM permeabilization during secondary necrosis, but may also proceed in the context of a regulated event, the so-called "permeability transition" (PT). Despite initial controversy, this term, PT, now is commonly used to identify the increase in IM permeability resulting from the activity of a multiprotein complex, the PTPC, that is assembled at the contact sites between OM and IM. Though the exact molecular composition of the PTPC has not been determined yet, an initial consensus has emerged about the main constituents of its scaffold structure. These include the abovementioned ANT, CypD and VDAC, but also hexokinase (a cytosolic protein that would interact with VDAC), creatine kinase (an IMS protein interacting with ANT and VDAC) and the peripheral-type benzodiazepine receptor (an $\mathrm{OM}$ integral protein). Additional factors that modulate the activity of the PTPC include pro- and anti-apoptotic proteins of the Bcl-2 family (for recent reviews see Refs. [49, 54]).

The exact mechanism by which the PTPC promotes MMP is also controversial. At least two models have been proposed to account for PTPC-mediated MMP. According to some authors, in physiological conditions VDAC would exist within the PTPC prominently in a low conductance state, in rapid equilibrium between the open and closed conformations [55]. Such a "flickering" PTPC would allow for the normal exchange of metabolites between the cytosol and the mitochondrial matrix. Upon pro-apoptotic insults, the longlasting opening of PTPC, associated with an increased conductance of VDAC, would result in $\Delta \Psi_{\mathrm{m}}$ dissipation, MMP and release of IMS proteins [56, 57]. An alternative model suggests that the high conductance state of VDAC would be associated with its physiological roles, whereas a closed conformation would lead to cell death, by favoring first a transient hyperpolarization, followed by osmotic imbalance, matrix swelling and finally OM rupture [58, 59]. However, results from electrophysiological experiments tend to undermine this interpretation (for a critical review see Ref. [60]).

It should be kept in mind that the mechanisms summarized above are not mutually exclusive but may cooperate to induce apoptosis. The relative weight of each may differ according to the specific cell death setting. However, MMP results in the release of apoptogenic IMS proteins, functional collapse of the mitochondria and apoptosis, irrespective of the initiator mechanism. Accordingly, the study of early mitochondrial alterations involving one or both mitochondrial membranes is crucial for the understanding of the 
mitochondrial regulation of apoptosis. To this aim, several methods based on fluorescence microscopy, cytofluorometry and other techniques have been optimized for routine laboratory use. Here, we will critically discuss the currently available methods for the detection of MMP affecting either IM or OM.

\section{Detection of OM permeabilization}

The most common technique for the detection of $\mathrm{OM}$ permeabilization consists in determining the subcellular redistribution of proteins that usually are retained within IMS by the OM. This may be achieved by immunoblot detection of such proteins (e.g. Cyt $c$, AIF) in different subcellular fractions (e.g. cytosol, mitochondria, nuclei). Alternatively, two-color immunofluorescence staining can be employed to visualize IMS proteins inside and outside of mitochondria, by determining their colocalization with sessile mitochondrial markers (e.g. heat shock protein of $60 \mathrm{kDa}$, i.e. HSP-60). Nuclear counterstaining and/or the use of other antibodies (e.g. specific for active caspases) may provide additional information about the apoptotic cascade (Fig. 1). Whereas AIF and Cyt $c$ are considered the prototypic IMS proteins released upon MMP (due to microinjection experiments of recombinant molecules in intact cells, which demonstrated that either proteins suffice to induce the nuclear manifestations of apoptosis [61, 62]), several other proteins are released from mitochondria upon
OM permeabilization $[63,64]$. These include but are not limited to adenylate kinase [65], Smac/Diablo [63], Omi/HtrA2 $[11,12]$, EndoG [17] as well as several pro-caspases [66].

Upon release from mitochondria, some of these proteins maintain a cytosolic localization (e.g. Smac/Diablo), whereas others translocate to the nucleus (e.g. AIF, EndoG) or interact with different subcellular compartments, like the endoplasmic reticulum (e.g. Cyt $c$ ). For the study of apoptosis-associated OM permeabilization, however, it should be kept in mind that IMS proteins are released following variable kinetics that depend not only on the protein, but also on the specific cell death model. For instance, it has been reported that AIF release may occur either before or after that of Cyt $c$ [16]. Moreover, small amounts of Cyt $c$ released through a partial OM permeabilization may participate in one or more feed-forward mechanisms that amplify MMP (for a review see Ref. [10]). The heterogeneity in the kinetics of IMS protein release may yield false negative (and more rarely false positive) results. This can be avoided by monitoring the subcellular localization of several IMS proteins rather than of a single one. Nevertheless, immunoblotting and immunofluorescence for the detection of OM permeabilization are time-consuming and only allow for the analysis of a limited number of samples. To achieve higher throughputs, immunoblotting may be replaced by miniaturized (96-well plate format) immunoassays based on the principle of the ELISA (enzyme-linked immunosorbent assay). Such assays are commercially available for the detection of Cyt $c$ and ensure a high degree of sensitivity $[67,68]$.
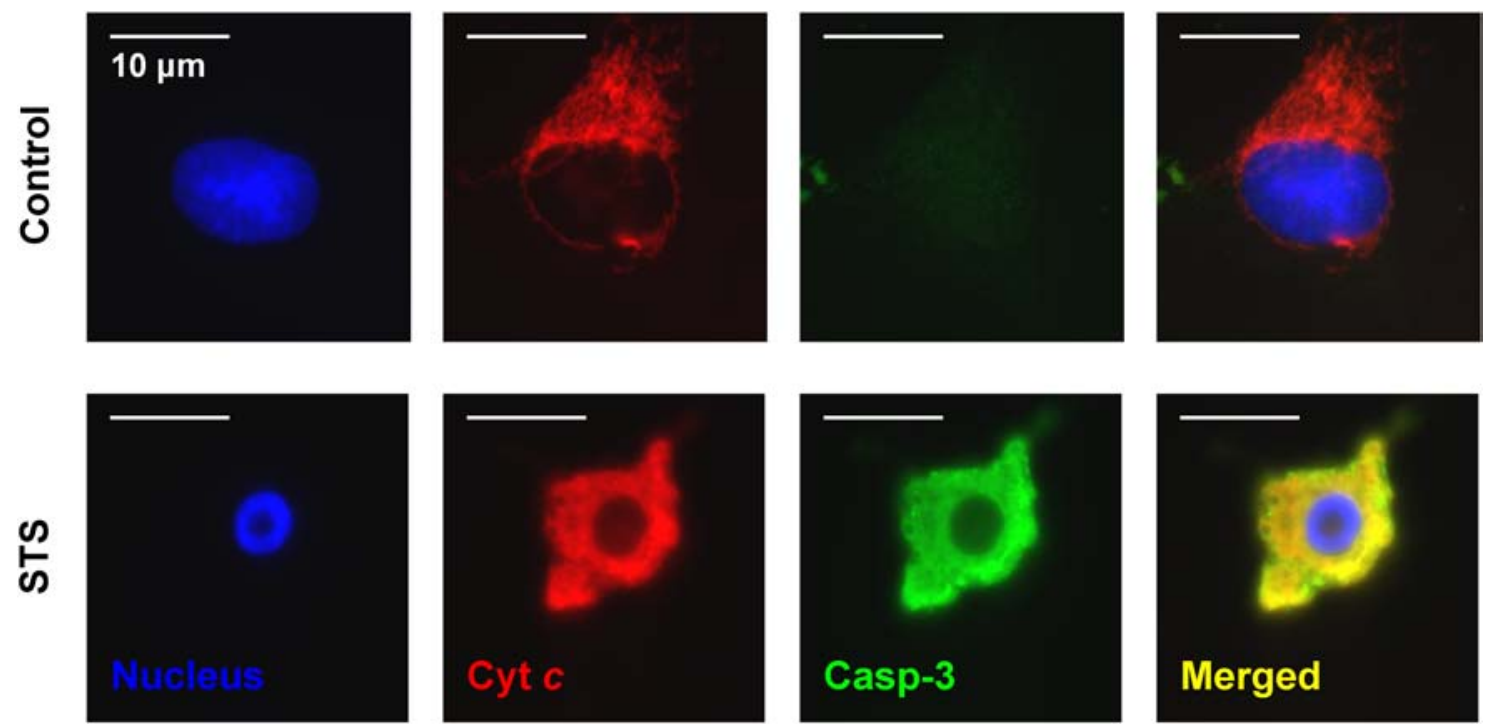

Fig. 1 Detection of OM permeabilization. H1975 cancer cells were left untreated or were incubated with $1 \mu \mathrm{M}$ staurosporine (STS) for $12 \mathrm{~h}$, followed by immunofluorescence staining with antibodies specific for Cyt $c$ and active caspase-3 (Casp-3), as well as counterstaining with Hoechst 33342 (which marks chromatin). In control cells (upper panels), Cyt $c$ is clearly retained in the IMS (as witnessed by the "tubu-

lar" pattern of fluorescence) and no active caspase-3 can be detected. Upon STS-induced mitochondrial membrane permeabilization (lower panels), Cyt $c$ is released in the cytosol (thus resulting in a more diffuse staining) where it leads to the activation of caspase-3. Please note also the pyknotic nucleus typical of cells undergoing apoptosis. White scale bars represent $10 \mu \mathrm{m}$ 
Recently, a cytofluorometric method for the immunodetection of Cyt $c$ following the digitonin-mediated permeabilization of plasma membrane has been proposed [69]. In the first step of the assay, plasma membranes (but not mitochondrial membranes) are permeabilized by low concentrations of digitonin, thus causing the wash out of cytosolic (but not mitochondrial) Cyt $c$ from the cells. Upon fixation, immunolabeling and cytofluorometric analysis, bright fluorescence identifies healthy cells that have retained Cyt $c$ within IMS, as opposed to cells that have released Cyt $c$ and that emit weak fluorescent signals [69]. Despite the theoretical possibility to process a large number of samples, this technique relies on a sophisticated permeabilization protocol, which may require repeated optimization (for instance depending on the cell type and on the digitonin stock).

OM permeabilization may be monitored in living cells by means of the stable or transient transfection with cDNA constructs encoding IMS proteins fused to a green fluorescent protein (GFP) moiety. Upon translation, these proteins (e.g. Cyt $c$-GFP or AIF-GFP chimeras) are imported into and retained within the IMS exactly as their normal counterparts, due to a mitochondrial localization sequence. Upon lethal insults, videomicroscopy may be employed to follow in real-time the subcellular re-localization of GFPtagged proteins from mitochondria to extramitochondrial compartments $[61,70]$.

In some instances, electron and immuno-electron microscopy have been used to detect ultrastructural changes in mitochondria of apoptotic cells. In this context, OM permeabilization has been visualized by means of ruptures in OM, through which IM herniation may occur [71, 72]. Obviously, gaps in OM induced by the osmotic swelling of the matrix are associated with an irreversible permeabilization, permanent mitochondrial dysfunction and release of IMS proteins. Accordingly, Cyt $c$ immuno-electron staining is lost in mitochondria with ruptured OM, whereas VDAC and the F1 subunit of ATPase remain associated with mitochondrial membranes [72]. Despite the large amount of additional information provided by electron microscopy, ultrastructural approaches are characterized by the following drawbacks: (1) they are laborious, and allow the analysis of a very limited number of samples; (2) they are not quantitative, because (unless hundreds of images are taken) they focus on few mitochondria of few cells; (3) they may fail to detect (unless IMS proteins are stained for immuno-electron determinations) the situations in which OM permeabilization has occurred through transient discontinuities or through the formation of supramolecular openings (e.g. when pro-apoptotic $\mathrm{Bcl}-2$ proteins are involved in the formation of multimeric channels). However, immuno-electron microscopy may be useful to visualize the precise sub-cellular localization of pro-apoptotic factors. For instance, immuno-electron mi- croscopy has been employed in association with confocal immunofluorescence technology to localize large Bax/Bak pore-forming oligomers (which have been suggested to account for $\mathrm{OM}$ permeabilization without irreversible membrane rupture) within or in the close proximity of OM $[42,43]$.

The integrity of the OM has also been determined by biochemical or biophysical assays, performed on subcellular fractions or isolated mitochondria. For instance, reversephase high-pressure liquid chromatography (HPLC) has been employed for the fast quantification (20 $\mathrm{min}$ for a single determination, as compared to time scales of hours for ELISA-based methods or days for immunoblots) of Cyt $c$ in mitochondrial samples, including pellets and supernatants arising from mitochondrial assays [73]. Moreover, HPLC may be used to quantify the diffusion of metabolites generated by IMS enzymes (e.g. phosphocreatine synthesized by creatine kinase) through OM [58, 59]. In a similar fashion, enzymatic activities of the respiratory chain (e.g. NADH oxidase) may be exploited to measure the accessibility to the IMS of exogenously administered substrates (e.g. NADH) [60]. This latter technique may indirectly assess the opening state of the transporters that are responsible for the diffusion of specific substrates (e.g. VDAC, which allows for the diffusion of NADH) [60].

Attempts have been undertaken to determine the intactness of the $\mathrm{OM}$ of isolated mitochondria by measuring Cyt $c$-dependent oxygen consumption [74]. According to this method, the exogenous supply of ascorbate-reduced Cyt $c$ promotes respiration only if the $\mathrm{OM}$ is permeabilized, thus allowing Cyt $c$ to reach Cyt $c$ oxidase on the outer leaflet of the IM [74]. Similar approaches may be applied also to entire cells. In this case, the prior permeabilization of the plasma membrane is required for the intracellular uptake of exogenous Cyt $c$ [75]. Table 1 summarizes the methods currently available for the detection of OM permeabilization.

\section{Detection of IM permeabilization}

Under normal circumstances, the $\Delta \Psi_{\mathrm{m}}$ ranges from 120 to $180 \mathrm{mV}$ (the intramitochondrial side being electronegative), according to the cell type. Thus, IM-permeant lipophilic cations accumulate in the mitochondrial matrix, driven by the $\Delta \Psi_{\mathrm{m}}$ following the Nernst equation, according to which every $61.5-\mathrm{mV}$ increase in membrane potential corresponds to a 10 -fold increase in the intramitochondrial concentration of monovalent cations. As a result, such cations are normally 2 to $3 \operatorname{logs}$ more concentrated in the mitochondrial matrix than in the cytosol, and cationic lipophilic fluorochromes may be used to measure the $\Delta \Psi_{\mathrm{m}}[76,77]$.

These fluorochromes include, but are not limited to rhodamine 123 ( $\mathrm{Rh}$ 123), tetramethylrhodamine 
Table 1 Detection of OM permeabilization

\begin{tabular}{|c|c|c|c|c|}
\hline Method & Technical platforms & Advantages & Drawbacks & Ref. \\
\hline \multicolumn{5}{|l|}{ Immunological methods } \\
\hline \multirow[t]{2}{*}{$\begin{array}{l}\text { Colocalization studies of } \\
\text { IMS proteins }\end{array}$} & $\begin{array}{l}\text { Fluorescence (confocal) } \\
\text { microscope }\end{array}$ & $\begin{array}{l}\text { Precise information on the } \\
\text { localization of IMS proteins } \\
\text { after release } \\
\text { No need for subcellular } \\
\text { fractionation }\end{array}$ & $\begin{array}{l}\text { Low throughput } \\
\text { It is recommended to monitor } \\
\text { more than a single IMS protein } \\
\text { to avoid false results }\end{array}$ & $\begin{array}{r}{[12,15,17} \\
63-66,98]\end{array}$ \\
\hline & Electron microscope & $\begin{array}{l}\text { High-resolution data on the } \\
\text { localization of IMS proteins } \\
\text { upon release }\end{array}$ & $\begin{array}{l}\text { Very low throughput } \\
\text { Scarcely representative of the } \\
\text { entire sample }\end{array}$ & {$[42,43,72]$} \\
\hline Immunoblotting & $\begin{array}{l}\text { Basic laboratory } \\
\text { equipment }\end{array}$ & $\begin{array}{l}\text { No need for dedicated } \\
\text { laboratory equipment }\end{array}$ & $\begin{array}{l}\text { Low throughput } \\
\text { Need for artifact-prone } \\
\text { subcellular fractionation }\end{array}$ & [98] \\
\hline $\begin{array}{l}\text { Cytofluorometric detection } \\
\text { of Cyt } c\end{array}$ & FACS & $\begin{array}{l}\text { Improved throughput } \\
\text { No need for subcellular } \\
\text { fractionation }\end{array}$ & $\begin{array}{l}\text { Need for selective } \\
\text { permeabilization of the plasma } \\
\text { membrane (difficult to achieve } \\
\text { without affecting the OM) }\end{array}$ & [69] \\
\hline ELISA & Plate reader & $\begin{array}{l}\text { High throughput } \\
\text { Commercial kits }\end{array}$ & $\begin{array}{l}\text { Need for subcellular } \\
\text { fractionation }\end{array}$ & {$[67,68]$} \\
\hline \multicolumn{5}{|l|}{ Other methods } \\
\hline Detection of Cyt $c$ & HPLC apparatus & Quantitative & $\begin{array}{l}\text { Need for subcellular } \\
\text { fractionation }\end{array}$ & [73] \\
\hline $\begin{array}{l}\text { Detection of IMS } \\
\text { metabolites } \\
\text { (e.g. phosphocreatine) }\end{array}$ & HPLC apparatus & $\begin{array}{l}\text { Quantitative } \\
\text { Data on the energetic stores of } \\
\text { mitochondria }\end{array}$ & $\begin{array}{l}\text { Need for subcellular } \\
\text { fractionation }\end{array}$ & {$[58,59]$} \\
\hline $\begin{array}{l}\text { Detection of exogenous } \\
\text { NADH oxidation }\end{array}$ & Spectrophotometer & $\begin{array}{l}\text { Additional information about } \\
\text { the opening state of VDAC }\end{array}$ & $\begin{array}{l}\text { Difficult interpretation of results } \\
\text { Applicable only to isolated } \\
\text { mitochondria }\end{array}$ & {$[60]$} \\
\hline $\begin{array}{l}\text { Detection of exogenous } \\
\text { Cyt } c \text { dependent oxygen } \\
\text { consumption }\end{array}$ & Clark-type electrode & $\begin{array}{l}\text { Semi-quantitative data on the } \\
\text { released Cyt } c \\
\text { Additional information on } \\
\text { mitochondrial respiration }\end{array}$ & $\begin{array}{l}\text { The application to in situ } \\
\text { mitochondria requires the } \\
\text { permeabilization of the plasma } \\
\text { membrane }\end{array}$ & {$[74,75]$} \\
\hline $\begin{array}{l}\text { Visualization of } \mathrm{OM} \\
\text { ruptures }\end{array}$ & Electron microscope & $\begin{array}{l}\text { Direct visualization of } \\
\text { mitochondria }\end{array}$ & $\begin{array}{l}\text { Very low throughput } \\
\text { Scarcely representative of the } \\
\text { overall sample } \\
\text { Failure to detect OM } \\
\text { permeabilization not associated } \\
\text { with physical discontinuities }\end{array}$ & {$[71,72]$} \\
\hline $\begin{array}{l}{ }^{1} \mathrm{H}-\mathrm{NMR} \text { studies of structured } \\
\text { mitochondrial water }\end{array}$ & NMR spectrometer & $\begin{array}{l}\text { Differentiation between } \mathrm{OM} \text { and } \\
\text { IM permeabilization } \\
\text { Identification of more complex } \\
\text { situations }\end{array}$ & $\begin{array}{l}\text { Low throughput } \\
\text { Need for subcellular } \\
\text { fractionation }\end{array}$ & [97] \\
\hline $\begin{array}{l}\text { Expression of GFP-tagged } \\
\text { IMS proteins }\end{array}$ & $\begin{array}{l}\text { Fluorescence (video) } \\
\text { microscope }\end{array}$ & $\begin{array}{l}\text { Detection of OM } \\
\text { permeabilization in living cells } \\
\text { (videomicroscopy) } \\
\text { Monitoring of rapid } \\
\text { permeabilization kinetics } \\
\text { (videomicroscopy) }\end{array}$ & $\begin{array}{l}\text { Low throughput } \\
\text { Need for construction and } \\
\text { optimization of the expression } \\
\text { plasmids }\end{array}$ & {$[61,70]$} \\
\hline
\end{tabular}

ethyl and methyl esters (TMRE and TMRM, respectively), chloromethyl-X-rosamine (CMXRos, also known as MitoTracker Red), 5,5',6,6'-tetrachloro-1,1',3,3'tetraethylbenzimidazolcarbocyanine iodide (JC-1) and 3,3' dihexyloxacarbocyanine iodide $\left(\mathrm{DiOC}_{6}(3)\right)$. Their spectral properties are summarized in Table 2.
Rh 123 is a cationic, cell-permeant fluorochrome characterized by rapid cellular uptake and equilibration (within a few minutes), that has been extensively used to stain mitochondria [78]. However, the application of Rh 123 to the measurement of $\Delta \Psi_{\mathrm{m}}$ is limited by the quenching of the dye at high concentrations $[77,79]$. As compared to Rh 123, 
Table 2 Spectral characteristics of the main $\Delta \Psi_{\mathrm{m}}$-sensitive probes for cytofluorometric analysis

\begin{tabular}{|c|c|c|c|c|}
\hline Probe & Chemical class & Absorption maximum & Emission maximum & Ref. \\
\hline Rh 123 & Rhodamine and derivatives & $507 \mathrm{~nm}$ & $529 \mathrm{~nm}$ (green) & {$[78]$} \\
\hline TMRE & Rhodamine and derivatives & $549 \mathrm{~nm}$ & $575 \mathrm{~nm}$ (red) & {$[77,82]$} \\
\hline TMRM & Rhodamine and derivatives & $543 \mathrm{~nm}$ & $573 \mathrm{~nm}($ red $)$ & {$[77,82]$} \\
\hline CMXRos (MitoTracker Red) & Rosamine and derivatives & $579 \mathrm{~nm}$ & $599 \mathrm{~nm}$ (red) & {$[77,84]$} \\
\hline JC-1 & Carbocyanine & $\begin{array}{l}\text { Monomers: } 498 \mathrm{~nm} \\
\text { J-aggregates: } 593 \mathrm{~nm}\end{array}$ & $\begin{array}{l}\text { Monomers: } 525 \mathrm{~nm} \text { (green) } \\
\text { J-aggregates: } 595 \mathrm{~nm} \text { (red) }\end{array}$ & [85-87] \\
\hline $\mathrm{DiOC}_{6}(3)$ & Carbocyanine & $484 \mathrm{~nm}$ & $501 \mathrm{~nm}($ green $)$ & {$[77,88]$} \\
\hline
\end{tabular}

Abbreviations: CMXRos, chloromethyl-X-rosamine; $\operatorname{DiOC}_{6}(3), 3,3^{\prime}$ dihexiloxalocarbocyanine iodide; JC-1, 5,5',6,6'-tetrachloro-1,1',3,3'tetraethylbenzimidazolcarbocyanine iodide; Rh 123, rhodamine 123; TMRE, tetramethylrhodamine ethyl ester; TMRM, tetramethylrhodamine methyl ester.

which we do not recommend for cytofluorometric analysis due to its aberrant behavior and to its toxicity in some experimental conditions [77, 80, 81], its derivatives (i.e. TMRE and TMRM) offer the significant advantage that they can be used at relatively low concentrations that do no induce relevant quenching effects [77]. High intramitochondrial concentrations, however, result in partial quenching of the fluorescent signal [82]. The accumulation of TMRE and TMRM within cells is even faster than that of Rh 123. Moreover, TMRM has been used (together with the $\mathrm{Ca}^{2+}$ indicator Fluo-5N) to develop a high-throughput assay for the detection of PT [83].

As compared to other mitochondrial probes, CMXRos provides the important advantage that it allows for formaldehyde fixation of cells before analysis. Thus, CMXRos may be employed to measure the $\Delta \Psi_{\mathrm{m}}$ in multi-color staining procedures, for instance in combination with antibodies against extra- and intracellular antigens or the TUNEL technique for the detection of apoptotic DNA fragmentation [84].

At low concentrations (aqueous solutions below $0.1 \mu \mathrm{M}$ ), JC-1 exists as a green-fluorescent monomer. At higher concentrations, as those which are attained in the mitochondria of healthy cells, JC-1 forms red-emitting "J-aggregates." Accordingly, the ratio of red-to-green JC-1 fluorescence can be used as a sensitive measure of the $\Delta \Psi_{\mathrm{m}}$, that is relatively independent of putative interfering factors, including mitochondrial mass, shape or density [85-87].

$\mathrm{DiOC}_{6}(3)$ has become the most commonly used carbocyanine fluorochrome for the cytofluorometric measurement of $\Delta \Psi_{\mathrm{m}}$ [88], due to its rapid mitochondrial equilibration and negligible quenching effects, at least at low concentrations (recommended dose 10-20 nM) [77, 89, 90]. However, higher concentrations of $\mathrm{DiOC}_{6}(3)$ result in relevant quenching and in the staining of non-mitochondrial compartments, such as the endoplasmic reticulum. The intensity of $\mathrm{DiOC}_{6}(3)$ fluorescence exhibit a partial dependence on the size of cells and on the plasma membrane potential. This does not represent a major concern when cell size is homogenous within the population and plasma membrane potential is not significantly modified by the experimental procedures. Otherwise, measurements of forward light scatter and other procedures can be used to normalize the results for cell size variability and magnitude of plasma membrane potential [88]. Several indo-, thia- and oxa-carbocyanines are currently available for the measurement of $\Delta \Psi_{\mathrm{m}}$, with specific features whose extensive description goes largely beyond the scope of the present review.

In selected cases, the measurement of $\Delta \Psi_{\mathrm{m}}$ may not be a reliable indicator of IM permeabilization. For instance, reduced $\Delta \Psi_{\mathrm{m}}$ may result from inhibited respiration, or from transient openings of the PTPC, not necessarily followed by IM permeabilization. The calcein quenching method (Fig. 2) may be employed to measure transient IM permeabilization events. According to this technique, cells are loaded with the fluorescent probe calcein, as well as with its quencher, cobalt $\left(\mathrm{Co}^{2+}\right)$ [91]. In its acetoxymethyl ester form, calcein diffuses to all subcellular compartments, including mitochondria, whereas $\mathrm{Co}^{2+}$ ions are excluded from the mitochondrial matrix by the $\mathrm{Co}^{2+}$-impermeable IM. Accordingly, a punctuate fluorescence signal identifies functional mitochondria, in healthy cells. Upon transient or permanent IM permeabilization (for instance following $\mathrm{Ca}^{2+}$ overload or oxidative insults), $\mathrm{Co}^{2+}$ enters the mitochondrial matrix and quenches the calcein fluorescence $[55,92]$. The calcein $/ \mathrm{Co}^{2+}$ technique has been adapted to confocal fluorescence microscopy [55] as well as to cytofluorometry [93].

Following IM permeabilization, solutes and water flood into the mitochondrial matrix, driven by the colloid osmotic pressure of the matrix that is tightly packed with enzymatic complexes. The resulting increase in mitochondrial matrix volume (known as "large-amplitude swelling") is accompanied by the distension and disorganization of the cristae as well as by a reduction of the electron density of the matrix [94]. These alterations can be used to assess PT, either in situ (for instance by electron microscopy) or in isolated mitochondria. Classically, light-scattering assays of rodent liver mitochondria in sucrose media have been employed [95]. In this case, large-amplitude swelling is monitored by measuring the absorbance of a mitochondrial suspension at $545 \mathrm{~nm}$, for instance in a conventional spectrophotometer [96]. This 
(a)

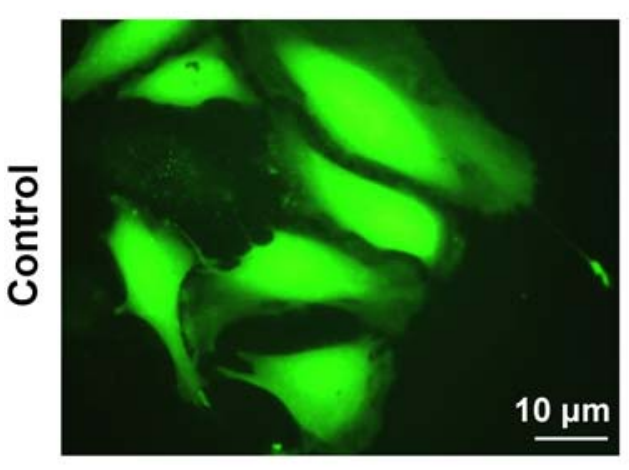

Calcein $+\mathrm{Co}^{2+}$

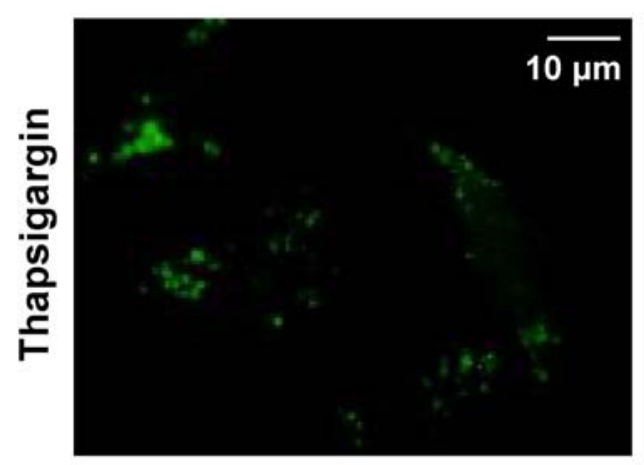

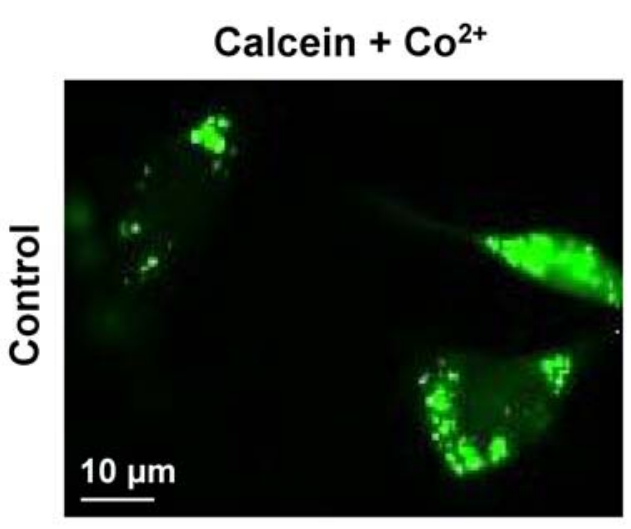

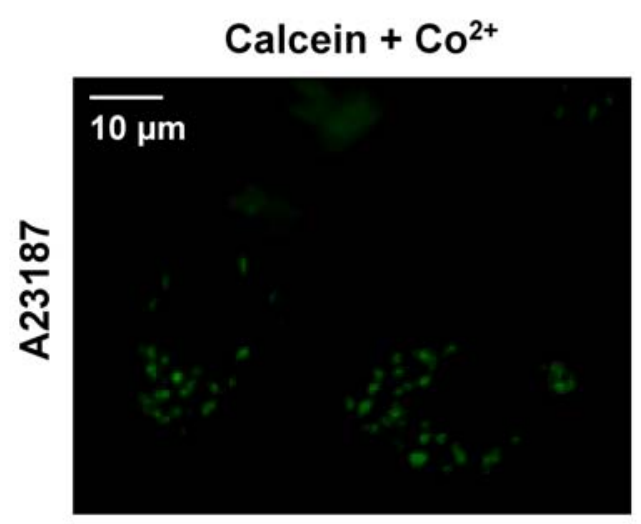

(b)

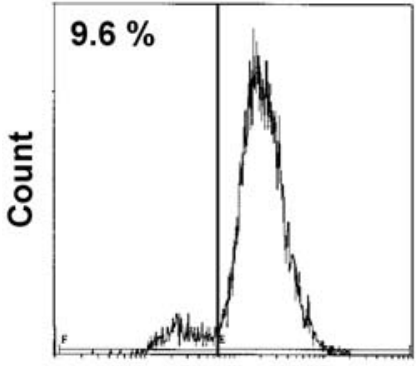

Calcein $+\mathrm{Co}^{2+}$
Thapsigargin

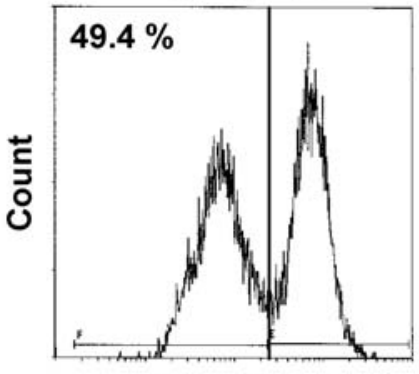

Calcein $+\mathrm{Co}^{2+}$

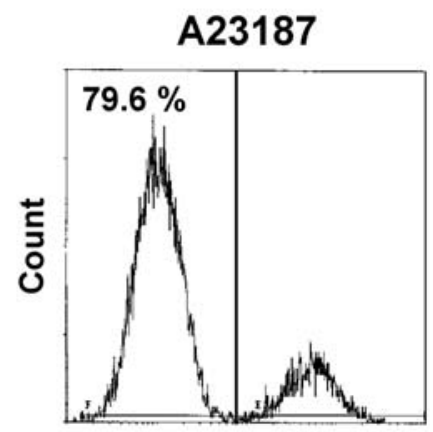

Calcein $+\mathrm{Co}^{2+}$

Fig. 2 Calcein $/ \mathrm{Co}^{2+}$ technique for the detection of IM permeabilization. HeLa cells were treated for $24 \mathrm{~h}$ with the endoplasmic reticulum toxin thapsigargin $(5 \mu \mathrm{M})$, the calcium ionophore A23187 $(5 \mu \mathrm{M})$, or left untreated (control). Thereafter they were stained with $1 \mu \mathrm{M}$ calcein acetoxymethyl ester in the presence or not of its quencher, cobalt $\left(\mathrm{Co}^{2+}\right)$. When $\mathrm{Co}^{2+}$ is added to healthy cells stained with calcein, the

cytosolic fluorescence is quenched and mitochondria appear as bright spots. Upon the administration of IM-permeabilizing agents, $\mathrm{Co}^{2+}$ ions gain access to the mitochondrial matrix where they further quench the calcein signal (a). Quantitative assessments of the calcein fluorescence may be performed by means of monoparametric FACS analysis (b). White bars correspond to $10 \mu \mathrm{m}$

technology has been adapted to 96-well plates for improved throughput [83].

Recently, a multiparametric flow cytometry approach has been proposed to measure the modifications of mitochondrial size, structure and $\Delta \Psi_{\mathrm{m}}$ associated with the onset of MMP [96]. Here, the authors correlated the structural rearrangements that characterize large-amplitude swelling with an increase in the forward scatter parameter (FSC) paral- leled by a decrease in the side scatter parameter (SSC) of isolated mitochondria. Reportedly, the ratio FSC/SSC represents a sensitive marker for PT, being able to detect morphological modifications on a per-organelle basis. Additional advantages of this method include the need for small amounts of mitochondrial suspensions (which may be important for the evaluation of rare samples from patients with mitochondrial disorders) and the possibility to analyze the 
heterogeneity of mitochondrial populations (which is not the case of classical spectrophotometric and fluorometric techniques) [96].

Proton nuclear magnetic resonance $\left({ }^{1} \mathrm{H}-\mathrm{NMR}\right)$ approaches have also been employed to characterize MMP [97]. Interestingly, the structured water (i.e. bound to macromolecules) inside mitochondria exhibits specific NMR properties following the opening of the PTP, as compared to other apoptotic settings (e.g. purified mitochondria incubated with recombinant Bax, or mitochondria isolated from rat liver undergoing apoptosis in vivo). Thus, the characterization of NMR parameters allows for the differentiation between OM and IM permeabilization, as well as for the identification of more complex scenarios (as those occurring in vivo) [97].

\section{Concluding remarks}

MMP represents a crucial check-point in the cascade of events leading to cell death, with far-reaching consequences for the pathophysiology of cell death, as well as for its pharmacological manipulation [7-9]. Thus, the meticulous investigation of the mechanisms of MMP is essential not only for a deeper comprehension of molecular biology phenomena, but also (and more importantly) to guide future therapeutical interventions. The conjunction of distinct techniques that measure MMP in its dual facets (i.e. OM vs. IM permeabilization), has allowed researchers to gain profound insights into the mechanisms underlying cell death. Nevertheless, future technical developments are needed to clarify the numerous questions about MMP that remain unanswered and to furnish reliable high-throughput assays for compound screening and diagnostic purposes.

Acknowledgments GK is supported by the "Ligue Nationale Contre le Cancer", the European Commission (RIGHT, Trans-Death, Active p53, Death-Train, Chemores) and INSERM.

\section{References}

1. Reed JC (2002) Apoptosis-based therapies. Nat Rev Drug Discov $1: 111-121$

2. Thompson CB (1995) Apoptosis in the pathogenesis and treatment of disease. Science 267:1456-1462

3. Kerr JF, Wyllie AH, Currie AR (1972) Apoptosis: a basic biological phenomenon with wide-ranging implications in tissue kinetics. Br J Cancer 26:239-257

4. Kroemer G, El-Deiry WS, Golstein P et al (2005) Classification of cell death: recommendations of the Nomenclature Committee on Cell Death. Cell Death Differ 12(Suppl 2):1463-1467

5. Zamzami N, Marchetti P, Castedo M et al (1996) Inhibitors of permeability transition interfere with the disruption of the mitochondrial transmembrane potential during apoptosis. FEBS Lett 384:53-57
6. Kroemer G, Zamzami N, Susin SA (1997) Mitochondrial control of apoptosis. Immunol Today 18:44-51

7. Kroemer G, Reed JC (2000) Mitochondrial control of cell death. Nat Med 6:513-519

8. Green DR, Kroemer G (2004) The pathophysiology of mitochondrial cell death. Science 305:626-629

9. Kroemer G, Galluzzi L, Brenner C (2007) Mitochondrial membrane permeabilization in cell death. Physiol Rev 87:99-163

10. Garrido C, Galluzzi L, Brunet M, Puig PE, Didelot C, Kroemer G (2006) Mechanisms of cytochrome $c$ release from mitochondria. Cell Death Differ 13:1423-1433

11. Martins LM, Iaccarino I, Tenev T et al (2002) The serine protease Omi/HtrA2 regulates apoptosis by binding XIAP through a reaper-like motif. J Biol Chem 277:439-444

12. Suzuki Y, Imai Y, Nakayama H, Takahashi K, Takio K, Takahashi $\mathrm{R}$ (2001) A serine protease, HtrA2, is released from the mitochondria and interacts with XIAP, inducing cell death. Mol Cell 8:613621

13. Du C, Fang M, Li Y, Li L, Wang X (2000) Smac, a mitochondrial protein that promotes cytochrome c-dependent caspase activation by eliminating IAP inhibition. Cell 102:33-42

14. Verhagen AM, Ekert PG, Pakusch M et al (2000) Identification of DIABLO, a mammalian protein that promotes apoptosis by binding to and antagonizing IAP proteins. Cell 102:43-53

15. Susin SA, Lorenzo HK, Zamzami N et al (1999) Molecular characterization of mitochondrial apoptosis-inducing factor. Nature 397:441-446

16. Modjtahedi N, Giordanetto F, Madeo F, Kroemer G (2006) Apoptosis-inducing factor: vital and lethal. Trends Cell Biol 16:264-272

17. Li LY, Luo X, Wang X (2001) Endonuclease G is an apoptotic DNase when released from mitochondria. Nature 412:95-99

18. Cain K, Bratton SB, Cohen GM (2002) The Apaf-1 apoptosome: a large caspase-activating complex. Biochimie 84:203-214

19. Daugas E, Susin SA, Zamzami N et al (2000) Mitochondrionuclear translocation of AIF in apoptosis and necrosis. Faseb $\mathrm{J}$ 14:729-739

20. Vahsen N, Cande C, Dupaigne P et al (2006) Physical interaction of apoptosis-inducing factor with DNA and RNA. Oncogene 25:1763-1774

21. Scaffidi C, Fulda S, Srinivasan A et al (1998) Two CD95 (APO-1/Fas) signaling pathways. EMBO J 17:1675-1687

22. Wajant $H$ (2002) The Fas signaling pathway: more than a paradigm. Science 296:1635-1636

23. Mehlen P, Bredesen DE (2004) The dependence receptor hypothesis. Apoptosis 9:37-49

24. Debatin KM, Krammer PH (2004) Death receptors in chemotherapy and cancer. Oncogene 23:2950-2966

25. Fuentes-Prior P, Salvesen GS (2004) The protein structures that shape caspase activity, specificity, activation and inhibition. Biochem J 384:201-232

26. Krammer PH (2000) CD95's deadly mission in the immune system. Nature 407:789-795

27. Zamzami N, El Hamel C, Maisse C et al (2000) Bid acts on the permeability transition pore complex to induce apoptosis. Oncogene 19:6342-6350

28. Gonzalvez F, Pariselli F, Dupaigne P et al (2005) tBid interaction with cardiolipin primarily orchestrates mitochondrial dysfunctions and subsequently activates Bax and Bak. Cell Death Differ 12:614-626

29. Goonesinghe A, Mundy ES, Smith M, Khosravi-Far R, Martinou JC, Esposti MD (2005) Pro-apoptotic Bid induces membrane perturbation by inserting selected lysolipids into the bilayer. Biochem J 387:109-118

30. Csordas G, Madesh M, Antonsson B, Hajnoczky G (2002) tcBid promotes $\mathrm{Ca}^{(2+)}$ signal propagation to the mitochondria: control 
of $\mathrm{Ca}^{(2+)}$ permeation through the outer mitochondrial membrane. EMBO J 21:2198-2206

31. Green DR, Kroemer G (1998) The central executioners of apoptosis: caspases or mitochondria? Trends Cell Biol 8:267-271

32. Zamzami N, Kroemer G (2003) Apoptosis: mitochondrial membrane permeabilization-the (w)hole story? Curr Biol 13:R71-73

33. Baines CP, Kaiser RA, Purcell NH et al (2005) Loss of cyclophilin $D$ reveals a critical role for mitochondrial permeability transition in cell death. Nature 434:658-662

34. Nakagawa T, Shimizu S, Watanabe T et al (2005) Cyclophilin D-dependent mitochondrial permeability transition regulates some necrotic but not apoptotic cell death. Nature 434:652-658

35. Halestrap AP, Brenner C (2003) The adenine nucleotide translocase: a central component of the mitochondrial permeability transition pore and key player in cell death. Curr Med Chem 10:1507-1525

36. Marchetti P, Castedo M, Susin SA et al (1996) Mitochondrial permeability transition is a central coordinating event of apoptosis. J Exp Med 184:1155-1160

37. Jacotot E, Ferri KF, El Hamel C et al (2001) Control of mitochondrial membrane permeabilization by adenine nucleotide translocator interacting with HIV-1 viral protein $\mathrm{rR}$ and Bcl-2. J Exp Med 193:509-519

38. Deniaud A, Brenner C, Kroemer G (2004) Mitochondrial membrane permeabilization by HIV-1 Vpr. Mitochondrion 4:223-233

39. Sabbah EN, Druillennec S, Morellet N, Bouaziz S, Kroemer G, Roques BP (2006) Interaction between the HIV-1 protein Vpr and the adenine nucleotide translocator. Chem Biol Drug Des $67: 145-154$

40. Wei MC, Zong WX, Cheng EH et al (2001) Proapoptotic BAX and BAK: a requisite gateway to mitochondrial dysfunction and death. Science 292:727-730

41. Wolter KG, Hsu YT, Smith CL, Nechushtan A, Xi XG, Youle RJ (1997) Movement of Bax from the cytosol to mitochondria during apoptosis. J Cell Biol 139:1281-1292

42. Kuwana T, Mackey MR, Perkins G et al (2002) Bid, Bax, and lipids cooperate to form supramolecular openings in the outer mitochondrial membrane. Cell 111:331-342

43. Nechushtan A, Smith CL, Lamensdorf I, Yoon SH, Youle RJ (2001) Bax and Bak coalesce into novel mitochondria-associated clusters during apoptosis. J Cell Biol 153:1265-1276

44. Basanez G, Sharpe JC, Galanis J, Brandt TB, Hardwick JM, Zimmerberg J (2002) Bax-type apoptotic proteins porate pure lipid bilayers through a mechanism sensitive to intrinsic monolayer curvature. J Biol Chem 277:49360-49365

45. Lucken-Ardjomande S, Martinou JC (2005) Newcomers in the process of mitochondrial permeabilization. J Cell Sci 118:473-483

46. Garofalo T, Giammarioli AM, Misasi R et al (2005) Lipid microdomains contribute to apoptosis-associated modifications of mitochondria in T cells. Cell Death Differ 12:1378-1389

47. Banerjee J, Ghosh S (2004) Bax increases the pore size of rat brain mitochondrial voltage-dependent anion channel in the presence of tBid. Biochem Biophys Res Commun 323:310-314

48. Rostovtseva TK, Antonsson B, Suzuki M, Youle RJ, Colombini M, Bezrukov SM (2004) Bid, but not Bax, regulates VDAC channels. J Biol Chem 279:13575-13583

49. Brenner C, Grimm S (2006) The permeability transition pore complex in cancer cell death. Oncogene 25:4744-4756

50. Mitchell P, Moyle J (1965) Evidence discriminating between the chemical and the chemiosmotic mechanisms of electron transport phosphorylation. Nature 208:1205-1206

51. Mitchell P, Moyle J (1965) Stoichiometry of proton translocation through the respiratory chain and adenosine triphosphatase systems of rat liver mitochondria. Nature 208:147-151

52. Zamzami N, Larochette N, Kroemer G (2005) Mitochondrial permeability transition in apoptosis and necrosis. Cell Death
Differ 12(Suppl 2):1478-1480

53. Zoratti M, Szabo I, De Marchi U (2005) Mitochondrial permeability transitions: how many doors to the house? Biochim Biophys Acta $1706: 40-52$

54. Crompton M, Barksby E, Johnson N, Capano M (2002) Mitochondrial intermembrane junctional complexes and their involvement in cell death. Biochimie 84:143-152

55. Petronilli V, Miotto G, Canton M et al (1999) Transient and long-lasting openings of the mitochondrial permeability transition pore can be monitored directly in intact cells by changes in mitochondrial calcein fluorescence. Biophys J 76:725-734

56. Shimizu S, Ide T, Yanagida T, Tsujimoto Y (2000) Electrophysiological study of a novel large pore formed by Bax and the voltage-dependent anion channel that is permeable to cytochrome c. J Biol Chem 275:12321-12325

57. Shimizu S, Narita M, Tsujimoto Y (1999) Bcl-2 family proteins regulate the release of apoptogenic cytochrome $\mathrm{c}$ by the mitochondrial channel VDAC. Nature 399:483-487

58. Vander Heiden MG, Chandel NS, Li XX, Schumacker PT, Colombini M, Thompson CB (2000) Outer mitochondrial membrane permeability can regulate coupled respiration and cell survival. Proc Natl Acad Sci USA 97:4666-4671

59. Vander Heiden MG, Chandel NS, Schumacker PT, Thompson CB (1999) Bcl-xL prevents cell death following growth factor withdrawal by facilitating mitochondrial ATP/ADP exchange. Mol Cell 3:159-167

60. Rostovtseva TK, Tan WMC (2005) On the role of VDAC in apoptosis: fact and fiction. J Bioenerg Biomembr 37:129-142

61. Loeffler M, Daugas E, Susin SA et al (2001) Dominant cell death induction by extramitochondrially targeted apoptosis-inducing factor. Faseb J 15:758-767

62. Zhivotovsky B, Orrenius S, Brustugun O, Doskeland S (1998) Injected cytochrome c induces apoptosis. Nature 391:449-450

63. Adrain C, Creagh EM, Martin SJ (2001) Apoptosis-associated release of Smac/DIABLO from mitochondria requires active caspases and is blocked by Bcl-2. EMBO J 20:6627-6636

64. Patterson SD, Spahr CS, Daugas E et al (2000) Mass spectrometric identification of proteins released from mitochondria undergoing permeability transition. Cell Death Differ 7:137-144

65. Kohler C, Gahm A, Noma T, Nakazawa A, Orrenius S, Zhivotovsky B (1999) Release of adenylate kinase 2 from the mitochondrial intermembrane space during apoptosis. FEBS Letters 447:10-12

66. Susin SA, Lorenzo HK, Zamzami N et al (1999) Mitochondrial release of caspase- 2 and -9 during the apoptotic process. J Exp Med 189:381-394

67. Anantharam V, Kitazawa M, Wagner J, Kaul S, Kanthasamy AG (2002) Caspase-3-dependent proteolytic cleavage of protein kinase Cdelta is essential for oxidative stress-mediated dopaminergic cell death after exposure to methylcyclopentadienyl manganese tricarbonyl. J Neurosci 22:1738-1751

68. van de Donk NW, Kamphuis MM, van Kessel B, Lokhorst HM, Bloem AC (2003) Inhibition of protein geranylgeranylation induces apoptosis in myeloma plasma cells by reducing Mcl-1 protein levels. Blood 102:3354-3362

69. Campos CB, Paim BA, Cosso RG, Castilho RF, Rottenberg $\mathrm{H}$, Vercesi AE (2006) Method for monitoring of mitochondrial cytochrome c release during cell death: immunodetection of cytochrome $\mathrm{c}$ by flow cytometry after selective permeabilization of the plasma membrane. Cytometry A 69:515-523

70. Goldstein J, Waterhouse N, Juin P, Evan G, Green D (2000) The coordinate release of cytochrome $c$ during apoptosis is rapid, complete and kinetically invariant. Nat Cell Biol 2:156-162

71. Feldmann G, Haouzi D, Moreau A et al (2000) Opening of the mitochondrial permeability transition pore causes matrix expansion and outer membrane rupture in Fas-mediated hepatic apoptosis in mice. Hepatology 31:674-683 
72. Terauchia S, Yamamotoa T, Yamashita K, Kataoka M, Terada H, Shinohara Y (2005) Molecular basis of morphological changes in mitochondrial membrane accompanying induction of permeability transition, as revealed by immuno-electron microscopy. Mitochondrion 5:248-254

73. Crouser ED, Gadd ME, Julian MW et al (2003) Quantitation of cytochrome c release from rat liver mitochondria. Anal Biochem 317:67-75

74. Mootha VK, Wei MC, Buttle KF et al (2001) A reversible component of mitochondrial respiratory dysfunction in apoptosis can be rescued by exogenous cytochrome $c$. EMBO J 20:661-671

75. Safiulina D, Kaasik A, Seppet E, Peet N, Zharkovsky A, Seppet E (2004) Method for in situ detection of the mitochondrial function in neurons. J Neurosci Methods 137:87-95

76. Castedo M, Ferri K, Roumier T, Metivier D, Zamzami N, Kroemer G (2002) Quantitation of mitochondrial alterations associated with apoptosis. J Immunol Meth 265:39-47

77. Metivier D, Dallaporta B, Zamzami N et al (1998) Cytofluorometric detection of mitochondrial alterations in early CD95/Fas/APO1-triggered apoptosis of Jurkat $\mathrm{T}$ lymphoma cells. Comparison of seven mitochondrion-specific fluorochromes. Immunol Lett 61:157-163

78. Johnson LV, Walsh ML, Chen LB (1980) Localization of mitochondria in living cells with rhodamine 123. Proc Natl Acad Sci USA 77:990-994

79. Schneckenburger H, Stock K, Lyttek M, Strauss WS, Sailer R (2004) Fluorescence lifetime imaging (FLIM) of rhodamine 123 in living cells. Photochem Photobiol Sci 3:127-131

80. Modica-Napolitano JS, Aprille JR (1987) Basis for the selective cytotoxicity of rhodamine 123. Cancer Res 47:4361-4365

81. Modica-Napolitano JS, Weiss MJ, Chen LB, Aprille JR (1984) Rhodamine 123 inhibits bioenergetic function in isolated rat liver mitochondria. Biochem Biophys Res Commun 118:717-723

82. Scaduto RC Jr, Grotyohann LW (1999) Measurement of mitochondrial membrane potential using fluorescent rhodamine derivatives. Biophys J 76:469-477

83. Blattner JR, He L, Lemasters JJ (2001) Screening assays for the mitochondrial permeability transition using a fluorescence multiwell plate reader. Anal Biochem 295:220-226

84. Macho A, Decaudin D, Castedo M et al (1996) Chloromethyl-XRosamine is an aldehyde-fixable potential-sensitive fluorochrome for the detection of early apoptosis. Cytometry 25:333-340

85. Cossarizza A, Baccarani-Contri M, Kalashnikova G, Franceschi C (1993) A new method for the cytofluorimetric analysis of mitochondrial membrane potential using the J-aggregate forming lipophilic cation 5,5',6,6'-tetrachloro-1,1',3,3'- tetraethylbenzimidazolcarbocyanine iodide (JC-1). Biochem Biophys Res Commun 197:40-45

86. Reers M, Smith TW, Chen LB (1991) J-aggregate formation of a carbocyanine as a quantitative fluorescent indicator of membrane potential. Biochemistry 30:4480-4486

87. Smiley ST, Reers M, Mottola-Hartshorn C et al (1991) Intracellular heterogeneity in mitochondrial membrane potentials revealed by a J-aggregate-forming lipophilic cation JC-1. Proc Natl Acad Sci USA 88:3671-3675

88. Rottenberg H, Wu S (1998) Quantitative assay by flow cytometry of the mitochondrial membrane potential in intact cells. Biochim Biophys Acta 1404:393-404

89. Petit PX, Lecoeur H, Zorn E, Dauguet C, Mignotte B, Gougeon ML (1995) Alterations in mitochondrial structure and function are early events of dexamethasone-induced thymocyte apoptosis. J Cell Biol 130:157-167

90. Zamzami N, Marchetti P, Castedo M et al (1995) Sequential reduction of mitochondrial transmembrane potential and generation of reactive oxygen species in early programmed cell death. J Exp Med 182:367-377

91. Huser J, Rechenmacher CE, Blatter LA (1998) Imaging the permeability pore transition in single mitochondria. Biophysical Journal 74:2129-2137

92. Nieminen AL, Byrne AM, Herman B, Lemasters JJ (1997) Mitochondrial permeability transition in hepatocytes induced by t-BuOOH: NAD(P)H and reactive oxygen species. Am J Physiol 272:C1286-1294

93. Poncet D, Boya P, Metivier D, Zamzami N, Kroemer G (2003) Cytofluorometric quantitation of apoptosis-driven inner mitochondrial membrane permeabilization. Apoptosis 8:521-530

94. Hunter DR, Haworth RA, Southard JH (1976) Relationship between configuration, function, and permeability in calcium-treated mitochondria. J Biol Chem 251:5069-5077

95. Bernardi P, Scorrano L, Colonna R, Petronilli V, Di Lisa F (1999) Mitochondria and cell death. Mechanistic aspects and methodological issues. Eur J Biochem 264:687-701

96. Lecoeur H, Langonne A, Baux L et al (2004) Real-time flow cytometry analysis of permeability transition in isolated mitochondria. Exp Cell Res 294:106-117

97. Pouliquen D, Bellot G, Guihard G, Fichet P, Meflah K, Vallette FM (2006) Mitochondrial membrane permeabilization produced by PTP, Bax and apoptosis: a 1H-NMR relaxation study. Cell Death Differ 13:301-310

98. Kluck RM, Bossy-Wetzel E, Green DR, Newmeyer DD (1997) The release of cytochrome $\mathrm{c}$ from mitochondria: a primary site for Bcl-2 regulation of apoptosis. Science 275:1132-1136 